\title{
Army Wives' Consumer Vulnerability and Communities of Coping
}

"There's absolutely no consideration for the army wife. They literally think it is the army wife's job to follow her husband and do as she's told"' (Jenny, Interviewee)

It is often said that when a person joins the Armed Forces, their whole family ultimately serves alongside them (Park, 2011), a view that is supported by the above excerpt. Military roles are typically highly demanding, characterised by long and unpredictable working hours, frequent relocation, extensive periods of time spent away from home during training or deployment, and the risk of injury or death in service (Rowe et al., 2014; Park, 2011). These factors also impact their spouses and partners (numbering in excess of 100,000 in the UK) (Ministry of Defence, 2018a; 2018b) who face regular relocation with accompanying disruptions to their social networks and employment. They must also manage the daily challenges associated with their partner's unpredictable working commitments alongside potential anxieties associated with the risk of harm to their serving partner (Keeling et al., 2015). Military spouses and partners represent key stakeholders for the UK Armed Forces and their resulting negative attitudes towards the military establishment can have a detrimental impact on serving personnel's performance, morale, and retention in role (Park 2011; Rosen et al. 1989). Statistics also indicate that the most frequently cited reason for premature retirement from a military career is the impact of service on family and personal life (Ministry of Defence, 2018b).

This study complements the wealth of research into the wellbeing of military personnel (e.g. Brooks and Greenberg, 2017) by exploring the experiences of non-serving women who marry UK Armed Forces personnel, in particular focusing on issues associated with their wellbeing. An important contributor to both objective and subjective elements of wellbeing is the extent to which individuals can participate freely within markets (Pavia and Mason, 2004; Visconti, 2016). In this paper we focus on the marketplace challenges faced by wives of army personnel 
(hereafter referred to as 'army wives'), and in particular their experiences with, and efforts to overcome, consumer vulnerability, which Baker et al. (2005) define as a lack of control within the marketplace that is detrimental to individuals' wellbeing. Consumer vulnerability is a state, rather than a persistent characteristic (Commuri and Ekici, 2008), which individuals are often able to address through the use of specific coping strategies (Baker et al., 2005). In contrast with the typically individualistic approaches to studies of coping (Hutton, 2016) we adopt a communities of practice lens. We recognise army wives' shared experiences and learned practices, deployed in pursuit of common goals (Wenger, 2000), to explore the potential for collective approaches to coping among army wives. Specifically, we pose two research questions (1) how might common characteristics of spouses' military roles result in shared consumer vulnerability among army wives? And (2) in what ways might membership of an army wives' community help women to cope with their experiences of consumer vulnerability?

We adopt a qualitative approach drawing on focus groups with army wives across four different locations in the UK and seven individual in-depth interviews. Our findings indicate that characteristics associated with military employment inform experiences of consumer vulnerability among army wives, which are shared, typically presenting barriers to the achievement of common goals (e.g. consumption, employment, leisure and socialising) with implications for their wellbeing. However, alongside this shared nature of vulnerability, heterogeneity among army wives informs individuals' experiences and subsequent coping strategies. We find that army wives may draw upon other army wives for support in addressing consumer vulnerability, thus integrating collective coping strategies alongside more commonly explored individual approaches. We therefore observe the potential for the local army wives collective to function as a community of coping, where the collective takes on a specifically supportive function, extending extant literature which typically overlooks the potential for communities of coping to provide both practical and emotional support. The extent to which 
army wives draw upon the community varies; in some instances women rely solely on individual coping strategies, exhibiting a reluctance to turn to the community or the existence of barriers (e.g. ostracism).

The remainder of this article is structured as follows: first, we introduce the context of our investigation before reviewing the literature on consumer vulnerability and communities of practice to clarify the research gaps. Subsequent sections detail the method, present findings, and discuss implications.

\section{LITERATURE REVIEW}

\section{The UK Armed Forces}

The UK's Armed Forces comprise the Army, The Royal Navy and Royal Marines, and the Royal Air Force. Collectively these institutions are responsible for defending the UK, overseas territories and Crown dependencies, as well as promoting wider interests such as international peacekeeping and providing humanitarian aid. (www.army.mod.uk; www.royalnavy.mod.uk; www.raf.mod.uk).

Roles within the Armed Forces vary widely. In addition to frontline infantry-type positions, military personnel might be employed within a range of functions, such as engineers, dog handlers, musicians, photographers, firefighters, HR and finance. Roles and responsibilities also vary according to rank; serving personnel are separated into other ranks or more senior officer ranks. Rank dictates salary, with the highest salaries commanded by those reaching the senior officer ranks. Some recruits enter the Armed Forces as an officer, others progress to an officer rank from other ranks, and many spend their entire career holding other ranks. Of the total number of current Armed Forces personnel, 19\% are officers with the remaining 81\% holding other ranks (Dempsey, 2018), indicating that the majority of military personnel receive a salary at the lower end of the scale. 
The UK military is often referred to as 'greedy' organisation as it demands total commitment and loyalty from its employees (Coser, 1967). Such expectations are manifested in extended periods away from home due to training, exercise, operation or deployment (Keeling et al., 2015), frequent requirements to relocate (sometimes overseas) (Jervis, 2011) and often long and unpredictable duty hours (Park, 2011). These long hours are reflected in Armed Forces recruitment campaigns, which promote "working, living and socialising" with colleagues who will be "your best mates" and describe the army as "a place to call home" (www.apply.army.mod.uk).

However, there is a potential conflict between the values expected of a military employee and those of a large proportion of military personnel: $53 \%$ are married, and a further $21 \%$ are in long-term relationships (Ministry of Defence, 2018b). Of these couples, 78\% have children (Ministry of Defence, 2018c). Those who are serving and are married or in civil partnerships (with or without children) can apply for Service Family Accommodation (SFA) which is located close to the serving person's place of work (www.AFF.org.uk). Given that military bases and roles are located throughout the UK, SFA is sometimes within large cities such as London and Edinburgh, and at other times is in extremely isolated and rural locales. Official UK government statistics indicate that $67 \%$ of army families, $57 \%$ of RAF families and 33\% of RN/RM families live in SFA (Ministry of Defence, 2018c). It is perhaps the combined benefits of guaranteed housing, military job security and a pension that transfers to the spouse in the event of the military employee's death that encourages military couples to marry at a younger age than the UK's wider population (Keeling et al., 2016; Ministry of Defence, 2018c).

Prior research has identified a number of enduring challenges for those who marry or form long-term partnerships with Armed Forces personnel. For example, frequent relocation hinders career development (Lyonette et al., 2018) and disrupts social and familial networks (Keeling 
et al., 2015), while the often unpredictable nature of military work schedules means that military spouses experience intermittent support from their serving partners (Park, 2011). Consequently, military partners can experience difficulties in achieving immediate and longerterm goals, and an overall detrimental impact on their wellbeing (De Burgh et al., 2011; Park, 2011).

In contrast to the rich volume of studies exploring the wellbeing of serving personnel, research into wellbeing among military partners is limited (Riggs and Riggs, 2011). In the next section we introduce the concept of consumer vulnerability, which we employ to inform our understanding of army wives' experiences within the marketplace, particularly focusing on the potential for feelings of not being in control. We propose that the military spouse community can help equip women to combat feelings and experiences of consumer vulnerability, ultimately helping them to realise more agentic responses, to support their wellbeing.

\section{Consumer Vulnerability}

Consumer vulnerability is described as a state of powerlessness that arises when people lack certain elements of control, leading to inequalities in the marketplace and subsequent difficulties in achieving consumption goals (Baker et al., 2005). Experiences of consumer vulnerability arise from the interaction of individual states, individual characteristics and external conditions within a context, where 'individual characteristics' include features such as socioeconomic status and biophysical concerns (e.g. addiction); the term 'individual states' refers to conditions such as grief or motivation; and 'external conditions' captures factors including social and economic dynamics (Baker et al., 2005). In deriving this consumer-driven and multi-dimensional conceptualisation, Baker et al. (2005) challenge so-called 'class-based' perspectives, which assume certain consumers are enduringly vulnerable (Commuri and Ekici, 
2008). Instead, their definition describes what consumer vulnerability is rather than who is vulnerable. Ultimately, anyone may experience consumer vulnerability.

Recent commentary has called for increased intersectional analysis in consumer vulnerability research, in order to capture the relevant individual states, individual characteristics and external conditions that act interdependently as triggers of consumer vulnerability (Saatcioglu and Corus, 2016a). To date, however, studies have predominantly focused on a single category as the basis of analysis. For instance, researchers applying Baker et al.'s (2005) conceptualisation have examined the vulnerability experienced as a result of individual characteristics such as age (Ford et al., 2016; Spotswood and Nairn, 2016), low literacy (Adkins and Ozanne, 2005), low income (Hamilton, 2012; Hutton, 2016) and visual impairment (Falchetti et al., 2016). Further studies have highlighted diverse external conditions that increase the likelihood of consumer vulnerability, including financial services providers' evolving lending criteria (Canhoto and Dibb, 2016), extreme weather events (Baker et al., 2007) and conflict among consumers occupying shared social spaces (Saatcioglu and Corus, 2016b).

A focus on individual experiences of consumer vulnerability predominates within prior research, with less emphasis on "collective, systemic, and status-based form[s] of vulnerability" (Saatcioglu and Corus, 2016a, p.32). However, Baker et al.'s (2007) and Baker and Baker's (2016) studies of tornado-hit communities highlight the potential for shared experiences, as multiple community members experienced consumer vulnerability simultaneously, due to the risks to safety, loss of homes and financial hardship that resulted from these extreme weather events. The military context offers the opportunity to further develop understanding of shared experiences of consumer vulnerability that are triggered by common spousal employment, while allowing us to account for women's range of individual states and characteristics. 
Individuals are often able to respond to experiences of consumer vulnerability through the use of specific coping strategies, drawing on a variety of resources and undertaking specific activities to address the associated imbalance in control (Adkins and Ozanne, 2005; Baker et al., 2005). Prior works have identified diverse coping strategies (e.g. Falchetti et al., 2016; Hamilton, 2012; Saatcioglu and Corus, 2016b), which are predominantly psychologicallyoriented, and emphasise individuals' means of coping and developing resilience. In contrast, Hutton (2016) evidences the relational nature of coping strategies among low-income women who develop resilience to economic adversity through actively discussing the relevant challenges with others who are impacted, and by purposefully protecting other people from the effects of economic adversity. Baker et al. (2007) and Baker and Baker (2016) highlight collective efforts by community members, such as the rebuilding of a school and putting on a Christmas parade, which sought to help a tornado hit town's residents recover and cope. Overall, however, the influence of the social context within which consumer vulnerability is experienced on subsequent coping strategies has been understudied. This is despite recognition elsewhere of the often collaborative nature of consumption goal achievement through such means as sharing (Belk, 2014) and value co-creation (Bruce et al., 2019; Gronroos and Voima, 2013).

In this paper, we seek to examine consumer vulnerability among the army wives' community and in particular explore the manner in which common characteristics of their husbands' employment in military roles may contribute. We draw on Baker et al. 's (2007) and Baker and Baker's (2016) observations that both individuals and communities can be transformed by their communal resources and explore how army wives move beyond the more commonly explored individually-focused coping strategies to incorporate more collective approaches. In doing so, we adopt a communities of practice lens, to which we turn in the next section. 


\section{Communities of Practice and Communities of Coping}

Communities of practice are defined as groups of people "that share cultural practices reflecting their collective learning" (Wenger 2000, p. 229); as such their study sheds light on the learning that emerges from the development of shared competencies and experiences (e.g. Brown and Duguid, 1991; Raz, 2007; Wenger et al., 2002). Communities of practice develop, and are continually negotiated, through the interplay of members' active participation and reflection upon the shared experiences around which their participation is centred (Wenger, 2010). The resultant informal, dynamic social structures develop and perpetuate practices in response to other structuring forces, such as institutions or management (Handley et al., 2006). The extent to which an individual participates in, and thus derives value from, a community of practice varies. Wenger (1998) distinguishes between peripheral and full participation, where the former refers to limited participation and the latter to more involved participation at the core of the community. A newcomer may move through a trajectory from peripheral to full participation, though some individuals prefer to remain at the periphery (Wenger, 1998).

The development of the communities of practice concept has seen it applied to studies within workplace settings, where the emphasis is on the collective sharing and social transmitting of often unofficial processes that facilitate community members in 'getting the job done' (Cox, 2005). While the potentially subversive nature of communities of practice is recognised (Cox, 2005), other studies seek to emphasise the potential benefits to the organisation as well as to their members (Lesser and Storck, 2001). For example, these include their capacity for knowledge building and sharing, collaborative problem solving, and business and strategy development (Wenger and Snyder, 2000; Pryko et al., 2017).

Understandings of communities of practice draw on the sense of a joint enterprise, with norms and relationships developed through mutual engagement and a shared repertoire of resources (e.g. languages, routines, stories, and styles) (Wenger, 2000). The emphasis is 
primarily on collective learning and the development of shared practices that reflect the means by which common goals are achieved. Within the army wives community, such shared practices reflect learning emanating from the military institution's expectations. Such expectations relate, for instance, to the attendance at and wearing of appropriate clothing to formal military functions, and the adherence to various rules associated with occupying SFA (Jervis, 2011). Discussions of communities of coping (Korczyski, 2003), on the other hand, provide specific recognition of the emotional support that these kinds of communities can provide for participants, enabling them to vent their work-related frustrations, discuss difficult situations, and seek empathy and understanding from colleagues (O'Donohoe and Turley, 2005). The resultant camaraderie and emotional support represent meaningful sources of coping for employees (Stroebaek, 2013). Prior research into communities of coping have focused on those emerging among service employees in specific workplace locations, such as offices or call centres, which are predicated on the proximate nature of employees and the potential for face-to-face, often spontaneous interactions. For example, Stroebaek (2013, p. 391) highlights the significance of shared coffee breaks as "informal, selective and spontaneous social structures" and identifies their role in enabling colleagues to share frustrations, and in facilitating the development of collective strategies for dealing with emotional challenges. In addition, communities of coping have been observed to emerge among dispersed service employees, such as migrant domestic workers (Jiang and Korczynski, 2016) and soldiers deployed to war zones (Godfrey and Brewis, 2018). Furthermore, Cohen and Richard's (2015) study of US retailer employees' use of social media evidences the potential for communities of coping to extend beyond face-to-face boundaries.

To date, understandings of communities of coping have primarily focused on the emotional support they provide. We attribute this to the context of these studies, since practical support can usually be provided from within the relevant organisational setting (e.g. by the Human 
Resources function) and also by the wider community of practice. However, our exploration within this alternative setting allows us to more fully consider how communities of coping can provide both practical and emotional means of coping with a range of circumstances. Our study therefore builds on work by Raz (2007), who observed emergent communities of call centre workers that drew on each other for practical (developing ways to circumvent restrictive operational procedures) and emotional support. In addition, Jiang and Korczynski's (2016) study highlights how a self-help group led by migrant domestic workers was specifically mobilised. This community of coping developed learning around practices that support the achievement of various practical benefits (e.g. legal understandings, language skills) as well providing emotional support from participation.

Despite empirical evidence of the potential benefits to individuals, discussions of communities of practice and communities of coping highlight possible challenges of membership, which can limit the extent of an individual's participation and the value they subsequently derive. For instance, intra-community conflict may occur where people bring conflicting norms from their membership of other social or familial groups (Wenger, 1998). Equally, newer members of communities of practice (e.g. new recruits to a firm) might be excluded from full participation by longer-standing members, should their insight and experiences pose a perceived threat to the community's values and knowledge (Handley et al., 2006). Empirically, Stroebaek (2013) highlights the difficulties faced by new colleagues in accessing communities of coping due to their sometimes spontaneous and informal nature. Moreover, at the individual level, membership of such communities provide a sense of selfidentity (Lesser and Storck, 2001), which may result in intra-person conflict where an individual is a member of multiple social systems with contrasting norms and values (Handley et al., 2006). 
While both communities of practice and communities of coping in consumer contexts are underexplored, literature suggests the potential for them to emerge. For instance, Schau et al. (2009) illustrate how consumer collectives organised around specific market offerings create value through shared practices associated with, for instance, sharing knowledge to enhance usage of the focal offering. Moreover, McColl-Kennedy et al. (2012) evidence the tendency among consumers to seek support from their wider social network during times of adversity. As we study a group of consumers who share common experiences and challenges (being married to a serving member of the army), framing our study with respect to communities of practice and associated communities of coping provides us with a lens to explore not only the potential for vulnerability amongst army wives but also both individual and collective means of coping.

\section{METHODOLOGY}

Data collection consisted of two stages. Focus groups were held in community centres at four different army bases in England. Focus groups were adopted in order to (1) build up an initial picture of experiences associated with being an army wife and identify future lines of inquiry, and (2) enable early exploration of individual and shared experiences of, and coping with, vulnerability among participants (Stewart and Shamdasani, 2014). To recruit participants we posted information about the study on dedicated army wives' Facebook pages and contacted the information centres serving the specific bases, who subsequently shared details of the project via their online notice boards and bulletins. Three of the focus groups were held in the evening while the fourth took place in the morning, during the community centre's regular coffee morning. Thirty army wives participated in this stage of study ${ }^{1}$. Table 1 provides details

\footnotetext{
${ }^{1}$ Our focus is on army wives given the range of different challenges and circumstances encountered by the wider military context (e.g. that which includes the Royal Navy, Royal Marines and Royal Air Force). We decided to focus on women only given that no men responded to our initial recruitment efforts and just $10 \%$ of military partners are men (Ministry of Defence, 2018c). This echoes the prior experiences of Lyonette et al. (2018), who made a concerted effort to include male spouses/partners, yet secured only $4 \%$ participation in their online survey and interviewed just two male spouses in their interviews.
} 
of focus group participants, all of whom lived in SFA. The length of time that the women had been married ranged from nine months to 25 years. With the exception of one participant who was married to an officer (Debbie, Base 4), all were married to personnel holding 'other ranks'.

\section{Insert Table 1 About Here}

Each group was jointly moderated by both researchers, one of whom has extensive experience of life within a military context while the other has more limited knowledge. This allowed the research team to adopt both 'insider' and 'outsider' statuses; the insider dimension has the potential to foster participant trust and openness, while the outsider dimension supports objectivity and reduces the risk of assumed similarities between researcher and participant experiences (Dwyer and Buckle, 2009), essentially facilitating "valuable insight precisely because of their outsider perspective" (e.g. asking what might be considered naïve questions) (Hayfield and Huxley, 2015, p. 92). All sessions were recorded and transcribed verbatim.

The second stage of the study involved seven one-to-one interviews with army wives. These participants consisted of: (1) three interviewees who had participated in the focus groups and were considered to have particularly relevant stories which we sought to explore in more depth; (2) four informants who demonstrated interest in the study but were unable to participate in the focus groups.

Table 2 summarises the interviewees' ages, locations, number of years married, employment status, and interview duration. All interviewees were married to personnel holding 'other ranks'. Interviews focused on exploring interviewees' experiences of consumer vulnerability in greater depth than the focus groups allowed. As far as possible these interviews were designed to resemble a conversation. In view of this, we only loosely followed an interview guide, but all interviews began with the following question: 'Can you start by telling us a bit about your life before you met your husband?' This was followed up by questions relating to their experiences of being an army wife (both positive and negative), with a 
particular focus on challenges they identified associated with consumption and the marketplace, and how they sought to manage these challenges.

\section{Insert Table 2 About Here}

We used NVivo software to aid our data analysis, which followed the completion of the focus groups. Our initial approach was inductive, drawing on elements of grounded theory (Glaser and Strauss, 1967). We first open coded all the data, and this provided the basis for the development of the coding framework. As we progressed through the second stage data set (interviews), we compared individual and focus group cases. During this process of revisiting the data our codes became more specific and we clarified these as we sought higher levels of abstraction, writing an agreed interpretation.

\section{FINDINGS}

Within our findings we first develop a picture of women's experiences of consumer vulnerability, we focus on those that were experienced by several of our participants, thus demonstrating how elements of consumer vulnerability can be shared. We establish elements of the military context and other structural elements that particularly inform these experiences. We then move on to specifically explore women's approaches to coping, encompassing both individual strategies, but most importantly for this paper, the extent to which the army wives community offers the potential for shared approaches to coping.

\section{Experiences of Consumer Vulnerability}

As the opening extract suggests, our participants' narratives are informed by a wider Armed Forces culture whereby women are perceived to provide a traditional support role for their 
husband in his military pursuits. Debbie, for instance, notes:

"There is still the assumption that, regardless if the wife is working, she is where the buck stops with the child care." (Debbie, Base 4, Focus Group)"

Our findings demonstrate how shared experiences of consumer vulnerability arise from a number of aspects associated with participants' husbands' military role and resultant family living conditions, specifically the location of military bases and SFA. Women's everyday experiences of vulnerability are also impacted by frequent relocation as well as aspects relating to the unpredictability of military working life. What might normally be considered everyday routines were often experienced as challenging, with participants attributing consumer vulnerability to obstacles surrounding the achievement of goals relating to marketplace activity, employment, and access to social and leisure activities. In the following sections we illustrate a range of army wives' experiences related to consumer vulnerability.

\section{Marketplace challenges and the potential for marketplace exclusion}

Military personnel typically have very little control over their postings (Keeling et al., 2015) meaning that their wives have limited influence over where they live (Table 1 includes an overview of participants' locations). While SFA is generally positioned within 10 miles of the serving personnel's place of work (www.AFF.org.uk), other amenities may be much further afield. Many of the women in our study reflected on these often-inconvenient locations and, in particular, shared stories about the distance to the nearest schools and the lack of public transport options.

"I think [overseas posting] was the hardest, when we moved to [city] because there was no secondary school provision. The nearest school was one and a half hours drive away." (Melanie, Focus Group, Base 1)

"I don't drive, and the first two weeks here I walked for fifty minutes to school with the girls each day and it was December and they were absolutely freezing. Then I thought: 'right, it's too cold', so I started taking a taxi each morning. They charged me a tenner [£10] there 
and back. But, yeah, found a friend and she now takes them. She's been doing that for maybe two and a half years." (Liz, Focus Group, Base 3)

Liz's story signals the potential importance of community support in offering solutions to daily challenges. This reliance on favours to carry out routine and essential journeys was a consistent theme in women's narratives around coping, upon which we expand in the next section. Many of our informants were not in employment at the time of study (see Table 1) and therefore reliant on a single income, often low due to the 'other rank' held by participants' spouses. These low income levels, as well as other factors (e.g. ill health or not having a driving license), meant that a number of our participants did not have access to a car and were reliant on the external provision of transport. The availability and knowledge of public transport was therefore important to access a number of essential services (e.g. health, education) with taxis providing a very costly alternative.

Participants also introduced the notion of marketplace exclusion (Hamilton, 2009) which even impacted those with their own transport. Here Jenny describes some of the challenges involved in buying essential items:

"There's not a shop here. You can't even buy a pint of milk. You have to drive and there's no parking in town, really. A bus would at least give you the flexibility to get into town but there aren't enough buses. You're excluded from everything like that." (Jenny, Base 4, Interview).

Marketplace exclusion may also arise due to the unpredictable nature of roles within the Armed Forces. Military work schedules are typically subject to change at short notice and extended periods of absence are also common (Keeling et al., 2015; Park, 2011). This has a far reaching impact on our participants' marketplace access; for example, they described the difficulties they faced making holiday arrangements:

"I would love to book a holiday in September for the following summer and get my child free spaces and pay it off month by month, but how can I do that when I don't know what's going to happen next August? We end up booking last minute, taking what we can get, and missing out on any of the discounts" (Nicola, Base 2, Focus Group) 


\section{Employment challenges and pressure on household income}

One of the key challenges for women seeking or maintaining employment was the frequency with which their spouses were required to relocate. As Table 1 indicates, this varied. Some women reported several moves within relatively short periods of time while others had spent longer periods in a given location before having to relocate. As Melanie explained, army wives may be forced to leave jobs when relocating, and experience difficulties in finding employment in new locations:

"I had a job, which I had to leave. That's the pattern. Every time we've moved, I've left a job and it's been months before I've found one again." (Melanie, Base 1, Interview)

These experiences extended the potential for marketplace exclusion through the limiting of household income levels, as Alice describes:

"Because of moving around all the time, you don't find work. We're always reliant on his income. And it is really bad. We live on one wage and we are scrimping and scraping; and it's especially hard when I can't find a job. " (Alice, Base 1, Focus Group)

Employment difficulties among army wives are compounded by additional external factors. For example legislation may prohibit army wives from working during overseas postings. However, more common, within our data, was the perception of discrimination by employers, who assume that army wives cannot commit for lengthy periods of time. This is illustrated in the following excerpt:

Lena: "I always get that sense that when they see military, you know, military wife on the $C V$...or, it's not on the $C V$, but it's pretty obvious from where you live.

Sheila: You're not a very good prospect, are you, if you're gonna be there for not very long.

Lena: Yeah...” (Base 4, Focus Group)

Remote locations and limited transport availability sometimes added to the challenge of finding suitable employment. Women who did work felt that the constraints associated with relocation negatively impacted the type of work they were able to do: 
"I gave up a career when I married my husband. I was a savings specialist in a building society. The next step for me was to become a financial advisor. I wanted to get a transfer but there wasn't a branch where we were going, so I just had to quit. Then fast forward five years I find myself working in the convenience store on camp." (Florence, Base 3, Focus Group).

This theme of stunted ambition was common (although we will discuss some of the varied means by which others secured and retained employment later). In addition to the resulting dependence on a single household income was the potential for women to feel a creeping sense of resentment at what they saw as a career sacrifice, again illustrated in the following extract:

"I've put my career on hold, even though I'm much better educated than my husband." (Lena, Base 4, Focus Group)

Employment-related challenges were further informed by the unpredictable nature of military schedules. The clearest impact of this unpredictability was on women with children, further highlighting the interplay of external characteristics associated with their husbands' military role and participants' individual characteristics (Baker et al., 2005). Being a military spouse often means living away from wider family, and subsequently taking on the main, or sometimes only, responsibility for childcare. Anna explains:

"I can't rely on him to be there, and childcare is only for certain hours, you know? A lot of the time, employers want flexibility; weekends, but he could be working. There's not a lot of childcare for weekends. Evenings as well. I was gonna find a job but then it's half term and he's away for that, so it's trying to find childcare for my two and there's no point, really. I haven't got any experience of any well paid job or anything like that." (Anna, Base 4, Focus Group)

As the above extract illustrates, women's employment opportunities were limited by the lack of parental support their partners could offer, and marketplace structures that meant childcare was either unavailable or too inflexible to support their needs. Anna's lack of prior work experience (an individual characteristic) also limits her opportunities. All these examples informed a challenging, if not impossible, environment for women to find and maintain employment, which impacted the household's income leading to further limits on their participation in the marketplace. 


\section{Potential exclusion from social and leisure activities}

Participants described how aspects of their husbands' military roles often prevented them from participating in social and leisure activities. Such experiences were again informed by the lack of amenities in the more remote locations, as Jenny describes:

"You can't go for a glass of wine or a beer because there is nowhere to go." (Jenny, Base 4 , Interview)

Alternatively, exclusion arose when relocation took families with children away from their support networks. Camille explains how this impacted her ability to socialise:

"When I get to a Friday night and think god, I could really just do with going to the pub this weekend and having a few drinks with some mates, I can't ring my mum and see if she'll come and watch the kids. I don't have that option. I don't get an outlet or a release." (Camille, Base 2, Focus Group).

Participants also signalled the potential for exclusion from social and leisure activities to arise due to their spouses' unpredictable work schedule and resultant lack of availability or reliability for childcare:

"That's it, I really want to do things like go to Zumba! But, if [husband] 's away I'm stuck in the house with the kids of an evening and I can't do anything." (Linda, Base 3, Focus Group)

In the following extract Jane again illustrates the impact of this unpredictability. However, in addition, the language she and her husband employ (he "will agree to babysit") clearly assigns the main responsibility for childcare to her:

"Hubby will agree to babysit but then he's like: 'oh, I've got to work late tonight, sorry love.' I'm like: 'oh, great, thank you'. There's always something that comes up!' (Jane, Base 3, Focus Group)

However, exclusion from social and leisure events was not limited to those with children. Jenny, for instance, describes how her husbands' changing work commitments can lead to planned leisure events being cancelled or missed, with the accompanying possibility of financial loss: 
"Last Christmas I got tickets to Kew Gardens, which cost about 40 pounds. We planned to go and then at the last minute [husband] was working. So I had no [husband] to go with. That was a bit heart-breaking." (Jenny, Base 4, Interview)

Furthermore, a normative couples culture within wider friendship groups can result in army wives being excluded from social events if their husband is unable to attend:

"Every time there's an invite to anything the caveat is always like, yeah, if he's around. I think it's a down side. Quite often when my friends do stuff I don't get invited because they know that the answer's going to be like: 'yeah, I'm coming by myself' and they're sort of: 'it'd be lovely to see you, but we're all coupled up and you're going to be a gooseberry'. I know there's stuff that I don't get invited to. (Patsy, Base 4, Focus Group)

As a result of these experiences there is the potential for army wives to feel a sense of social isolation (Hamilton, 2009), with possible detrimental impacts on their wellbeing:

"You're isolated, you're on your own. And I did develop anxiety. I never had anxiety before. Never. Never. Because I never felt isolated; but being in area where you don't know, and you don't have many friends, it's a daunting prospect." (Ria, Base 4, Interview)

We now turn to a consideration of women's individual and collective approaches to coping with consumer vulnerability and associated marketplace exclusion.

\section{Coping with Consumer Vulnerability}

Participants described a variety of individual and collective strategies for coping with consumer vulnerability that they had developed over time and with experience. Individual strategies typically take the form of psychological responses, such as "being independent", "having a positive mental attitude" and "being emotionally strong" so you can "push through the hard times". Participants also described "detaching from the army life" and "keeping a little bit of yourself", suggesting a desire among participants for a sense of self that deprioritises an identity as an army wife, whose primary role it is to support her spouse in his military career. Behavioural strategies were also evident, with participants discussing the importance of "pushing yourself out there to meet people" in order to facilitate social and leisure activities, 
and thus combat social isolation, and the need to circulate your CV in advance of relocation in order to generate possible employment opportunities. To further address the challenges surrounding employment, some participants had become self-employed in occupations that enabled them to generate income flexibly around their husband's unpredictable schedule and in the event of relocation. For instance, participants had trained in hairdressing and beauty therapy, or had become home-based sales representatives. While extolling the benefits of this strategy, self-employed participants also reflected upon the challenges associated with developing a client base when moving to a new area, not least because of the popularity of this coping strategy among army wives and the subsequent competition for business and the associated low incomes.

Collective coping strategies entail army wives drawing upon each other for support, the nature of which varied; for instance, participants highlighted assistance of a practical nature, such as impromptu childcare or transport, that allows an individual to attend work or a social event. Such arrangements were described as informal and reciprocal, and demonstrated that army wives' communal activities often went beyond the learned practices associated with communities of practice (e.g. those that enable members to 'get the job done', where the 'job' in this instance might reflect a diversity of goals associated with being an army wife, such as wearing the correct clothing to official functions or adhering to SFA rules). Participants highlighted the benefits of receiving emotional support from fellow army wives who, due to their similar experiences, were able to empathise with the challenges being faced. Consequently, in addition to functioning as a community of practice, army wives communities can facilitate the formation of communities of coping, which emerge as specific, specialised sub-groups that provide members with both practical and emotional means of coping with consumer vulnerability (Korczynski, 2003; Raz, 2007; Wenger et al., 2002). 
Overall approaches to coping with consumer vulnerability differed among our participants; as we highlight in Table 2, individuals integrated collective coping strategies with individual approaches to varying degrees. To illustrate, we next present examples of different approaches to coping with consumer vulnerability based mainly on the stories of three participants: Sally, Jenny and Nicola.

\section{Sally: Maintaining distance from the community of coping}

Sally is thirty eight and has been married to Jim for eight years. Jim's four school-age children from a previous relationship live with Sally and Jim on a permanent basis. They live in SFA in the North of England. We describe Sally as an independent coper as she draws exclusively on individual strategies to address the consumer vulnerability that arises from the characteristics of Jim's work.

For instance, prior to their most recent move, Sally enjoyed a successful sixteen-year career in HR, working for a large organisation with offices in numerous locations throughout the country. Following previous moves, Sally retained her role by relocating to offices commutable from her accomodation, enabling her to continue to build her career. However, her employer's lack of presence within their current area led to an extended career break with an agreement that she would recommence her HR career with her employer in the future. During this period, Sally has broadened her skill set through formal training, which has allowed her to enhance her $\mathrm{CV}$ and work on a part-time basis. Sally thus avoids some of the employment challenges and limitations described by other participants, as she describes:

"I'd done 16 years and three days when I went on my career break. I only decided to do that because we were getting posted and there were no jobs for me. When we move again I can go back to work. I've been doing my own thing in the meantime. Last year I went to college, and I trained to be a teaching assistant, and then I worked at school on the camp, I did one day a week. And then this year I do one day a week at a different school." 
Sally acknowledges the presence of a local army wives community of practice and associated community of coping:

"There is a community here. I do the school run and people say: 'hello', but I just do my own thing. When we first moved here, I made an effort to get to know people and another wife asked: 'is there any chance I could borrow £40?' They waste their money then end up borrowing off each other. I would never ask for anyone to lend me money, especially when I hardly know them. So, I lied and said: 'oh, I'm really sorry but I haven't got that money'. I also find a lot of the wives are always moaning, and I'm thinking: 'Why are you being so negative? Why choose to sit and home and moan?' I keep myself to myself."

Sally is reticent to to provide practical (in the form of a loan) or emotional support for other army wives, and thus purposefully avoids participating in the community of coping (Korczynski, 2003). She reveals difficulty in empathising with other wives (whom she describes as 'moaning') and actually positions herself as peripheral to the wider community of practice with her use of language ('they waste their money'). Sally's preferred peripheral participation and resultant individual approach is informed by a perceived incongruity between her personal values and those of other army wives, which constitutes a barrier to more extensive participation:

"Most, army wives are quite young, not educated, bleached blond hair, have a couple of children, and are trash. They think things are owed to them, they don't need to work for them. They didn't need to pass their exams. Their kids are at school, and they don't do anything, just sit in the café all day. I want more than that. I've got my career and a job. I go out, I go to the gym, I've been doing slimming world. There's lots to do."

Sally's narrative indicates a deliberate reluctance to participate in the army wives community of practice as a whole, whereas for others this reticence was specifically focused around the community of coping; for instance, Holly:

"People have said to me: just ask and we'll have [son] or whatever. But I feel that that's me showing a sign of weakness and that I can't cope. So I don't ask for the help." (Holly, Base 2, Focus Group)

Therefore, it seems that despite the presence of communities of coping, army wives may actively limit their participation and choose instead to draw upon their individual resources and 
coping strategies in dealing with consumer vulnerability and associated marketplace challenges.

\section{Jenny: Peripheral community of coping member}

Forty four-year old Jenny has been married to Ben for eight years. She is educated to degree level, works full time in a logistics role and lives with Ben in SFA in the South of England. They have no children. Like Sally, Jenny has developed individual coping strategies to enable her to overcome consumer vulnerability. As the following excerpt describes, she draws upon her individual resources (e.g. social, financial and ability to drive) to address the challenges associated with living in a remote location:

"My way of dealing with living here is to spend as little time here as possible. I base my life outside of where we live. I basically spend pretty much every minute that I'm not at work on a train to London to spend time with my friends there. I basically just fork out the money, drive to the station and pay to park the car."

However, unlike Sally, Jenny has integrated collective coping with her individual approaches. Her community of coping comprised of a small group of army wives who lived in close proximity, and whose husbands worked in the same military unit. Members provided practical support to each other in the form of reciprocal transport arrangements, which enabled them to address the exclusion from social and leisure activities that arose due to their remote location and poor public transport services. Jenny describes:

"If one of us was going out on a Friday night I'd say: 'well, I'm staying in, I'll come and get you from the train station', and then the next time she'd come and get me from the train station. Because the buses here are so infrequent and taxis are so expensive, we'd rather drive each other about and have a sober night and know that there's a lift there when we needed it."

Unfortunately, this community of coping dissolved when all the members apart from Jenny relocated with their husbands. It seems, therefore, that although communities of coping can emerge as key means of support for army wives experiencing consumer vulnerability, one of the characteristics of military employment that can trigger consumer vulnerability (relocation) 
can also render the community temporary in nature; communities of coping are not an inevitable aspect of being part of a community of practice. Jenny has since faced challenges in accessing a similar community of coping in her area, and her involvement can be described as peripheral, at best. In contrast with Sally, the barriers perceived by Jenny relate to a sense of being excluded from the wider community of practice:

"There's a lot of wives whose husbands work together, but not with mine, and they go to their own mess functions and things like that. They have a large community and it's not easy to get an invite into that. I've been to a couple of things at people's houses and tried to speak to people, but I didn't get invited again. They all know each other through their kids as well. So, as a wife with no kids whose husband does a different job in the army, I feel very much ostracised from the rest of the military community here."

Jenny's experience demonstrates how the consciousness of kind associated with communities (Muniz and O'Guinn, 2001) could also be exclusionary; in this case her not having children and her husband's unique role provide important markers as to her likely contribution to the community (or perhaps just as importantly, what the community might be able to offer her). Jenny's difficulties in accessing the community could suggest that as a new member she is seen by others as a potential threat to the community's values and knowledge (Handley et al., 2006), and this combines with other aspects to make the community less accessible. Her experiences illustrate how communities of practice and their associated communities of coping are not available to all, and this was illustrated by other participants who variously described experiences of exclusion due to full time employment, having children of different ages to other wives, and not living in SFA, all of which can make it difficult to meet people and form relationships. Some accounts described established communities of practice as unwelcoming to newcomers, or as unfriendly due to inherent hierarchies that form as members assume the rank of their serving husband, as Florence recounts:

"It was my first move, and this women in the toddler group said: 'what rank are you, love?' I was like: 'oh no, you must be confused, I'm not in the army, my husband is'. She said: 'Yes, I know, what rank are you?' I never went back to toddler group. ' (Florence, Base 3, Focus Group). 
Such experiences left little opportunity for women to draw on the collective for support of any kind. Our findings suggest, therefore, that army wives who seek to integrate collective and individual coping strategies in response to consumer vulnerability can sometimes face systemic barriers to doing so, which ultimately limits their participation in communities of coping and the potential support they might receive.

\section{Nicola: Full community of coping member}

Nicola is thirty two and has been married to Rob for five years. They have two children aged three and five. Nicola, Rob and the children live in SFA in the North of England. Nicola left school at eighteen and completed vocational qualifications in childcare, rising to the level of pre-school deputy manager before their most recent move. She currently works part time in an auxiliary medical role. Her employment is flexible and allows her to work shifts as and when Rob's schedule allows. However, this means that Nicola's contribution to the household income varies greatly; some months she brings home only a few hundred pounds, meaning that they are often largely reliant on Rob's income. In contrast to Jenny, whose primary social network lies outside the army wives community (her friends in London), Nicola has formed relationships with other local army wives; she draws on this community of coping extensively, in addition to deploying individual strategies. For example, the community provides Nicola with ad hoc childcare that enables her to work:

"I rely on the other wives to pick the kids up when Rob's going to be late home and I've got a shift."

In addition to this practical support, the community provides Nicola with emotional support:

"Just having that friendship, somebody that you can talk to who knows what it's like to be in the same situation, you know, when you get pissed off because your husband says: 'I've got to work late' or 'I'm going away again'. Other people, they don't understand. They live in a different bubble." 
Here Nicola eludes to a factor that may inform the emergence of these communities of coping: a perceived lack of empathy among the non-military population that discourages army wives from seeking support outside the army context. This was echoed by other participants who described how people without military connections often assume incorrectly that military wages are high and that SFA is luxurious and free. A common irritation was the assumption from others that they should have known what to expect:

"If I'm in a bit of a state where I've had a bad day and my husband's away, I ring my mum or [husband]'s mum and they're like: 'well, you knew what you were getting yourself into'. And I said to his mum: 'if you were to say that to my face, I would smack you!' Because you don't know 100 per cent what you're getting into or how you're going to feel until you're there." (Holly, Base 2, Focus Group)

In contrast to Sally's deliberate non-participation in the community of coping, Nicola is a full and active member, both deriving support and offering it to other members. However, Nicola also notes a potential negative impact of this participation, as she describes:

"The community is the best bit and the worst bit. Everyone knows your business. Anything that would happen at Rob's work, other wives would know about it. Say Rob's got told off for something, and somebody's husband went and told their wife, then they went and told somebody else, you know?"

Other participants highlighted this potentially darker side to the community. Ria, who has more limited engagement with the community of coping, notes how offputting she initially found this aspect of the community to be:

"When we first moved here I went to a family day, but it was all just bitching! Bitching about neighbours: 'Number 20 hasn't cleaned her curtains for a while' or 'Did you hear about her husband sleeping with such and such?' And I sat there thinking: we're all in this together, we should be supporting each other, not judging each other. I remember thinking: I can't do this."

Ria's unease seems to suggest a contrast between what she wants from the community and her perception of the membership norms (Wenger, 1998). Consequently, in addition to providing valuable means of coping, participating in the army wives community could also have negative outcomes. 


\section{DISCUSSION}

This study investigated army wives' shared experiences of consumer vulnerability and associated marketplace exclusion and their subsequent strategies for coping with these experiences. We have shown how specific characteristics of military roles can trigger experiences of consumer vulnerability among army wives, who attribute their experiences to common challenges around access to markets and amenities, employment, and social and leisure pursuits. We enrich existing knowledge regarding the factors underlying consumer vulnerability by evidencing characteristics of spousal employment as a potential external characteristic (Baker et al., 2005). In this section we discuss the theoretical implications of our findings, identifying distinct contributions to knowledge.

First, we observe that army wives' experiences of consumer vulnerability are outcomes of the interplay between common characteristics of their spouses' military roles and the women's individual characteristics (Baker et al., 2005), which include factors such as poor health, limited work experience and motherhood. Thus, by drawing on the army wives context we are able to demonstrate that while aspects of consumer vulnerability can be shared, heterogeneity will ultimately create individual differences within such experiences. Consequently, we enrich the narrative around shared consumer vulnerability. While prior studies have evidenced common challenges faced simultaneously by multiple community members (Baker et al., 2007; Baker and Baker, 2016), they have largely overlooked the potential for individual differences within these shared experiences. Moreover, we highlight the relevance of intersectionality to army wives' experiences of consumer vulnerability (Saatcioglu and Corus, 2016a) to demonstrate the potentially cumulative nature of these individual differences (e.g. disability, health, education).

Second, in exploring the means by which army wives address consumer vulnerability, we note that while individual psychologically-oriented coping strategies are frequently drawn 
upon (Falchetti et al., 2016; Hamilton, 2012) army wives may also deploy collective strategies by participating in communities of coping. The adoption of a community of practice lens builds on the works of Baker et al. (2007) and Baker and Baker (2016) to facilitate a fuller understanding of collective responses to consumer vulnerability. We extend prior understandings to recognize the varying extents to which individual and collective strategies are integrated (see Table 2). This was an exploratory study and we are not in a position to identify specific wider patterns or explanations as to the varying degrees of involvement in communities of coping. Our findings do suggest that army wives with younger children are more likely to participate more fully in such communities, due to a common need for ad hoc childcare and an ability to reciprocate in kind. However, participants without children also described reciprocal support (e.g. caring for pets; lifts) and not all women with children engaged with communities of coping. Our data also suggest that army wives in employment were more likely to display peripheral involvement in the community of coping or to rely solely on independent coping, as were those who were older, had married at a later age or had older, more self-sufficient children.

Some women maintained a deliberate distance from the community of practice as a whole, given a perceived incongruence between their identity and values and those of the army wives community. In other scenarios, army wives experience barriers to participation in the form of ostracism and exclusion by existing members. We add further insight to the knowledge of how communities of practice can inform collective coping, acknowledging the existence of fluidity and accompanying disruption (e.g. in this case when core members relocate with their spouses).

Our third contribution is to extend understandings of communities of practice and communities of coping beyond the immediate employment context. Studies in non-workplace settings are rare and we therefore enhance current knowledge of these social learning systems by evidencing their emergence and role within a consumer context. Moreover, whereas prior 
studies have predominantly explored a collective as either a community of practice (e.g. Wenger and Snyder, 2001) or a community of coping (e.g. Korczyski, 2003), we illustrate how communities of coping can emerge from wider communities of practice, providing members with varied forms of practical and emotional support in coping with consumer vulnerability (Korczynski, 2003; Raz, 2007; Wenger et al., 2002).

\section{CONCLUSIONS}

Where people experience consumer vulnerability and associated negative impacts on their wellbeing, governments and their agencies are often called upon to take action to alleviate the problem (Baker et al., 2007). However, in this case the UK government is implicated in the conditions that trigger consumer vulnerability; these women face common challenges due to their spouses' employment in a government service. By reducing the unpredictability associated with military roles, for example in terms of working schedules and relocation, the government would lessen the negative impact of military employment on the wives of serving personnel. However, given the overall purpose of the UK Armed Forces and their need to respond quickly and effectively to a diversity of events (www.army.mod.uk; www.royalnavy.mod.uk; www.raf.mod.uk), such change is perhaps unlikely.

A more realistic recommendation is a change in the currently patriarchal Armed Forces culture so that wives are no longer expected to prioritise their spouses' military commitments over all else, and are afforded reasonable expectations and rights to active agency and equal opportunities in their career and life choices (Hyman et al., 2005). Ideally, this cultural shift would also acknowledge that Armed Forces personnel have important roles to play at home and with their families, reflecting developments both in the UK and further afield, for workplaces to recognise employees' parenting roles (e.g. O'Brien, 2013). A change in culture might manifest in leadership practices that afford flexibility to serving personnel who need, for 
instance, to be available at certain times to take care of their children or who wish to remain in a given location due to their wife's career.

Organisational cultural change is, however, a long and complex process (Cameron and Quinn, 2011). In the shorter term, the UK government might invest in a series of initiatives that would reduce experiences of consumer vulnerability among military spouses while not acting to the detriment of the Armed Forces. For instance, providing low-cost public transport and childcare services would support army wives' marketplace activities, employment and social and leisure pursuits. Alternatively, they might invest in new SFA in areas that are less remote and better served by key amenities. We recognise the potentially high costs of these initiatives but contend that the size of any investment should be weighed against the continued costs of recruiting and training personnel to replace those who leave prematurely due to the pressures of military life on their families (Ministry of Defence, 2018b).

The UK government could also consider more carefully the value of a supportive spouse community. The introduction of formal practices and posts, such as positions with community based responsibilities could work alongside the established welfare functions, with a particular focus on welcoming new members and developing social events and leisure activities for army spouses. Such an approach should recognise the heterogeneity among army wives and benefit spouses regardless of their employment status. Of course, our data demonstrate that some army wives prefer to remain at the periphery of the spouse community but such an initiative would recognise the benefits of communities of practice and the potential for these to develop into communities of coping.

Some limitations of our study are evident. Our participants were based in the UK at the time of data collection, and while many reflected on prior overseas postings, the predominant focus was on their current location and most recent experiences. Our means of recruitment may have inadvertently encouraged participation from more active members of the army wives 
community of practice whilst discouraging others, for example those who do not live in SFA or whose position as an army wife is not central to their sense of self. However, these women may also experience consumer vulnerability as a result of their military spouse's occupation.

Future research might seek to develop understandings of consumer vulnerability and associated coping strategies among a more diverse sample of military spouses and partners. This might include spouses and partners of other military personnel whose experiences may differ from those of army wives; for example, Royal Navy and Royal Marine families are less likely to live in SFA yet are more likely to experience long periods of separation (six months or more) (Ministry of Defence, 2018b), and due to officer's higher salaries, it is possible that officers wives' experiences of consumer vulnerability may differ from those of wives of 'other ranks' who largely comprised our sample. In addition, we explored individuals' collective coping within their local army wives community; future investigations might explore military spouses' engagement in communities of coping that emerge in online environments, such as social media. 


\section{References}

Adkins, N. R. and Ozanne, J. L. (2005), “The low literate consumer”, Journal of Consumer Research, Vol. 32 No.1, pp. 93-105.

Baker, S. M., Gentry, J. W. and Rittenburg, T. (2005), "Building understanding of the domain of consumer vulnerability", Journal of Macromarketing, Vol. 25 No. 2, pp. 128139.

Baker, S. M. and Baker, C. N. (2016), "The bounce in our steps from shared material resources in cultural trauma and recovery", Journal of the Association for Consumer Research, Vol. 1 No. 2, pp. 314-335.

Baker, S. M., Hunt, D. M. and Rittenburg, T. L. (2007), "Consumer vulnerability as a shared experience: Tornado recovery process in Wright, Wyoming", Journal of Public Policy \& Marketing, Vol. 26 No. 1, pp. 6-19.

Belk, R. (2014), "You are what you can access: Sharing and collaborative consumption online”, Journal of Business Research, Vol. 67 No. 8, pp. 1595-1600.

Brooks, S. and Greenberg, N. (2017), "Non-deployment factors affecting psychological wellbeing in military personnel: Literature review", Journal of Mental Health, Vol. 27 No. 1, pp. 80-90.

Brown, J. S. and Duguid, P. (1991), "Organizational learning and communities-of-practice: Toward a unified view of working, learning, and innovation", Organization Science, Vol. 2. No. 1, pp. 40-57.

Bruce, H. L., Wilson, H. N., Macdonald, E. K. and Clarke, B. (2019), "Resource integration, value creation and value destruction in collective consumption contexts", Journal of Business Research, Vol. 103, 173-185.

Cameron, K. and Quinn, R. E. (2011), Diagnosing and Changing Organizational Culture: Based on the Competing Values Framework (3rd ed.), Jossey-Bass, San Francisco, California.

Canhoto, A. I. and Dibb, S. (2016), "Unpacking the interplay between organisational factors and the economic environment in the creation of consumer vulnerability", Journal of Marketing Management, Vol. 32 No. 3-4, pp. 335-356.

Cohen, N. and Richards, J. (2015), “'I didn't feel like I was alone anymore': Evaluating selforganised employee coping practices conducted via Facebook", New Technology, Work, and Employment, Vol. 30 No. 3, pp. 222-236.

Commuri, S. and Ekici, A. (2008), "An enlargement of the notion of consumer vulnerability, Journal of Macromarketing, Vol. 28 No. 2, pp. 183-186.

Coser, L. A. (1967), "Greedy organizations", European Journal of Sociology, Vol. 8 No. 2, pp. 196-215. 
Cox, A. (2005), "What are communities of practice? A comparative review of four seminal works", Journal of Information Science, Vol. 31 No. 6, pp. 527-540.

De Burgh, H. T., White, C. J., Fear, N. T. and Iversen, A. C. (2011), “The impact of deployment to Iraq or Afghanistan on partners and wives of military personnel", International Review of Psychiatry, Vol. 23 No. 2, pp. 192-200.

Dempsey, N (2018), "House of Commons briefing paper: UK defence personnel statistics", available at: https://researchbriefings.parliament.uk/ResearchBriefing/Summary/CBP7930\#fullreport (accessed $7^{\text {th }}$ February 2019).

Dwyer, S. C. and Buckle, J. L. (2009), "The space between: On being an insider-outsider in qualitative research", International Journal of Qualitative Methods, Vol. 8 No. 1, pp. 5463.

Falchetti, C., Ponchio, M. C. and Botelho, N. L. P. (2016), "Understanding the vulnerability of blind consumers: Adaptation in the marketplace, personal traits and coping strategies", Journal of Marketing Management, Vol. 32 No. 3-4, pp. 313-334.

Ford, N., Trott, P. and Simms, C. (2016), "Exploring the impact of packaging interactions on quality of life among older consumers", Journal of Marketing Management, Vol. 32 No. 3-4, pp. 275-312.

Glaser, B. and Strauss, A. (1967), The Discovery of Grounded Theory: Strategies for Qualitative Research, Aldine, Chicago.

Godfrey, R., \& Brewis, J. (2018), "Nowhere else sells bliss like this: Exploring the emotional labour of soldiers at war", Gender, Work \& Organization, Vol. 25 No. 6, pp. 653-669.

Grönroos, C. and Voima, P. (2013), "Critical service logic: making sense of value creation and co-creation", Journal of the Academy of Marketing Acience, Vol. 41 No. 2, pp. 133150 .

Hamilton, K. (2009), "Low-income families: experiences and responses to consumer exclusion", International Journal of Sociology and Social Policy, Vol. 29 No. 9/10, pp. 543-557.

Hamilton, K. (2012), "Low-income families and coping through brands: Inclusion or stigma?” Sociology, Vol. 46 No. 1, pp. 74-90.

Handley, K., Sturdy, A., Fincham, R. and Clark, T. (2006), "Within and beyond communities of practice: Making sense of learning through participation, identity and practice", Journal of Management Studies, Vol. 43 No. 3, pp. 641-653.

Hayfield, N. and Huxley, C. (2015), "Insider and outsider perspectives: Reflections on researcher identities in research with lesbian and bisexual women", Qualitative Research in Psychology, Vol. 12 No. 2, pp. 91-106.

Hutton, M. (2016), "Neither passive nor powerless: Reframing economic vulnerability via resilient pathways", Journal of Marketing Management, Vol. 32 No. 3-4, pp. 252-274. 
Hyman, J., Scholarios, D. and Baldry, C. (2005), "Getting on or getting by? Employee flexibility and coping strategies for home and work", Work, Employment and Society, Vol. 19 No. 4, pp. 705-725.

Jervis, S. (2011), Relocation, Gender and Emotion: A Psycho-Social Perspective on the Experiences of Military Wives, Routledge, New York.

Jiang, Z., \& Korczynski, M. (2016), "When the 'unorganizable'organize: The collective mobilization of migrant domestic workers in London", Human Relations, Vol. 69 No. 3, pp. 813-838.

Keeling, M., Wessely, S., Dandeker, C., Jones, N. and Fear, N. T. (2015), "Relationship difficulties among U.K. military personnel: Impact of sociodemographic, military, and deployment-related factors", Marriage and Family Review, Vol. 51 No. 3, pp. 275-303.

Keeling, K., Wessely, S. and Fear, N.T. (2016), "Marital status distribution of the U.K. military: Does it differ from the general population?" Military Behavioral Health, Vol. 5 No. 1, pp. 26-34.

Korczynski, M. (2003), "Communities of coping: Collective emotional labour in service work”, Organization, Vol. 10 No. 1, pp. 55-79.

Lesser, E. L. and Storck, J. (2001), "Communities of practice and organizational performance”, IBM Systems Journal, Vol. 40 No. 4, pp. 831-841.

Lyonette, C., Baines, S.A., Kispeter, E., Fisher, N. and Newell, K. (2018), “Military spousal/partner employment: Identifying the barriers and support required", available at: https://aff.org.uk/resources/military-spousal-partner-employment-identifying-the-barriersand-support-required/ (accessed $7^{\text {th }}$ February 2019).

McColl-Kennedy, J. R., Vargo, S. L., Dagger, T. S., Sweeney, J. C. and Kasteren, Y. V. (2012), "Health care customer value cocreation practice styles", Journal of Service Research, Vol. 15 No. 4, pp. 370-389.

Ministry of Defence (2018a), "UK armed forces quarterly service personnel statistics: $1^{\text {st }}$ October 2018, published November $15^{\text {th }} 2018$ ", available at: https:/www.gov.uk/government/statistics/quarterly-service-personnel-statistics-2018 (accessed $7^{\text {th }}$ February 2019).

Ministry of Defence (2018b), "UK regular armed forces continuous attitude survey results 2018", available at: https:/www.gov.uk/government/statistics/armed-forces-continuousattitude-survey-2018 (accessed $7^{\text {th }}$ February 2019).

Ministry of Defence (2018c), "UK tri-service families continuous attitude survey results 2018", available at: https://assets.publishing.service.gov.uk/government/uploads/system/uploads/attachment d ata/file/728466/TriService Families Continuous Attitude Survey 2018 Main Report.pd $\underline{f}$ (accessed $7^{\text {th }}$ February 2019). 
Muniz, A. M. and O'Guinn, T. C. (2001), "Brand community". Journal of Consumer Research, Vol. 27, No. 4, pp. 412-432.

O'Brien, M. (2013), "Fitting fathers into work family policies: international challenges in turbulent times", International Journal of Sociology and Social Policy, Vol. 33 No. 9/10, pp. 542-564.

O'Donohoe, S. and Turley, D. (2006), "Compassion at the counter: Service providers and bereaved consumers", Human Relations, Vol. 59 No. 10, pp. 1429-1448.

Pavia, T. M. and Mason, M. J. (2004), "The reflexive relationship between consumer behavior and adaptive coping", Journal of Consumer Research, Vol. 31 No. 2, pp. 441454.

Park, N. (2011), "Military children and families: Strengths and challenges during peace and war", American Psychologist, Vol. 66 No. 1, pp. 65-72.

Pyrko, I., Dörfler, V. and Eden, C. (2017), "Thinking together: What makes Communities of Practice work?” Human Relations, Vol. 70 No. 4, pp. 389-409.

Raz, A. (2007), "Communities of practice or communities of coping?” The Learning Organization, Vol. 14 No. 4, pp. 375-387.

Riggs, S. A. and Riggs, D. S. (2011), "Risk and resilience in military families experiencing deployment: The role of the family attachment network", Journal of Family Psychology, Vol. 25 No. 5, pp. 675-687.

Rosen, L. N., Moghadam, L. Z. and Vaitkus, M. A. (1989), "The military family's influence on soldier's personal morale: A path analytic model”, Military Psychology, Vol. 1 No. 4, pp. 201-213.

Rowe, S. L., Keeling, M., Wessely, S. and Fear, N. T. (2014), "Perceptions of the impact a military career has on children", Occupational Medicine, Vol. 64 No. 7, pp. 490-496.

Saatcioglu, B. and Corus, C. (2016a), "An inclusive approach to consumer vulnerability: exploring the contributions of intersectionality", in Hamilton, K., Dunnett, S. and Piacentini, M. (Eds.), Consumer Vulnerability: Conditions, Contexts and Characteristics, Routledge, London, pp. 45-56.

Saatcioglu, B. and Corus, C. (2016b), "Exploring spatial vulnerability: Inequality and agency formulations in social space", Journal of Marketing Management, Vol. 32 No. 3-4, pp. $230-251$.

Schau, H. J., Muñiz Jr, A. M. and Arnould, E. J. (2009), "How brand community practices create value", Journal of Marketing, Vol. 73 No. 5, pp. 30-51.

Segal, M. W. (1986), "The military and the family as greedy institutions", Armed Forces and Society, Vol. 13 No. 1, pp. 9-38. 
Spotswood, F. and Nairn, A. (2016), "Children as vulnerable consumers: A first conceptualisation”, Journal of Marketing Management, Vol. 32 No. 3-4, pp. 211-229.

Stewart, D. W. and Shamdasani, P. N. (2014), Focus groups: Theory and Practice, Sage, Los Angeles.

Stroebaek, P. S. (2013), "Let's have a cup of coffee! Coffee and coping communities at work", Symbolic Interaction, Vol. 36 No. 4, pp. 381-397.

Visconti, L. M. (2016), “A conversational approach to consumer vulnerability:

Performativity, representations, and storytelling", Journal of Marketing Management, Vol. 32 No. 3-4, pp. 371-385.

Wenger, E. (1998), “Communities of practice: Learning as a social system”, Systems Thinker, Vol. 9 No. 5, pp. 2-3.

Wenger, E. (2010), "Communities of practice and social learning systems: The career of a concept", in Blackmore C. (Ed.), Social Learning Systems and Communities of Practice, Springer, London, pp. 179-198.

Wenger, E., McDermott, R. A. and Snyder, W. (2002), Cultivating Communities of Practice: A Guide to Managing Knowledge, Harvard Business Press, Boston.

Wenger, E. C. and Snyder, W. M. (2000), "Communities of practice: The organizational frontier”, Harvard Business Review, Vol. 78 No. 1, pp. 139-146. 